\title{
Innovative Strategic Leader Transforming From a Low-Cost Strategy to Product Differentiation Strategy
}

\author{
R. Ray Gehani
}

\begin{abstract}
After the 2008 economic slowdown, and with increasing assault from enterprises from emerging economies, many innovative strategic leaders of multinational enterprises are forced to radically transform their enterprises. They often choose to change from low-cost strategy to innovation-driven product differentiation strategy. In this study, we use a multi-level Grounded Theory Methodology (GTM) and agency theory to empirically illustrate such a strategic transformation at a large composite fabric and accessories enterprise. Lessons are drawn from the impact of strategic transformation at multiple levels: strategic leader level, tactical-team manager level, operational follower level, and stakeholder level. Implications for practitioners and researchers are provided by way of mindful leader orientation and value-based innovation.
\end{abstract}

Keywords: technology management; innovation driven strategy; innovative leader; mindful leader; leader-member exchange (Imx) theory; value-based innovation.

Director - Graduate Programs in Global Technology Innovation.The University of Akron. 259 South Broadway, Akron, Ohio 44308. E-mail: rgehani@uakron.edu. 


\section{Introduction}

In the aftermath of 2008 financial recession, with a heightened intensity of rivalry from emerging economies, it became unsustainable to pursue low-cost leadership strategy for many leading global enterprises such as Eastman Kodak, Goodyear,Timken, Nokia, General Motors, General Electric, and Joanne Fabrics. A new generation of innovative leaders at these global enterprises attempted to transform their business-level strategy from low-cost leadership strategy to product-differentiation strategy (Gamble and Gehani, 20I3). With offshore outsourcing of manufacturing and service enterprises to low cost countries, there has been increasing commoditization of goods and services with shrinking profit margins.

According to Porter (1980), the firms pursuing low-cost leadership strategy are constantly under attack from rivals pursuing product differentiation strategy trying to reduce their costs. And firms pursuing product differentiation strategy may see threats from their rivals pursuing low cost leadership strategy trying to innovate their products. It has, therefore, become imperative for the strategic leaders of the enterprises pursuing low-cost leadership strategy to transform their enterprises towards product differentiation strategy. To sustain their competitive advantages, these enterprises must erect high barriers to entry for their rivals by going beyond their incremental improvements and transforming themselves into radically innovating enterprises with protected proprietary intellectual property or unique distribution channels. Very few studies elaborate how innovative strategic leaders transform their enterprises from low-cost strategy to product differentiation strategy (Gamble and Gehani, 2013).

\section{Steve Jobs's Second Coming To Apple}

Many strategic leaders of innovative U.S. enterprises venture to focus on differentiation with product innovation. For example, when Apple co-founder Steve Jobs returned to Apple in 1997, he asserted that Apple should be producing primarily differentiated and premium-priced computers instead of low-cost clones. Jobs urged his tactical team managers that these innovative products must be well designed, well-made computers for the top segment of the market - just like luxury cars (Kahney, 2008: 3I). Jobs noted that most car manufacturers like Chevrolet change their products incrementally from one model to the next, even though many customers are willing to pay premium prices for a BMW compared to a Chevy.

Jobs emphasized that Apple was always under pressure to sell more computers at lower cost. But he did not want Apple to compete in the low-cost computer market, which was a race to the bottom with commoditization. He noted that the low-cost computer makers such as Compaq, Gateway, Acer, Lenovo, and even Dell, were making essentially similar commodity-like computers which competed primarily on low price.

Jobs envisioned that Apple would produce top-class innovative products to make enough profits to keep funding and developing more top-class innovative products. And, Jobs was able to execute this strategic transformation successfully when Apple was barely three months away from bankruptcy. With this strategic transformation, the market value of Apple sky-rocketed from $\$ 3$ billion a decade ago to $\$ 340$ billion in 2012 (Anthony and Christensen, 2012).

Innovative leaders must change continually and re-invent themselves from time to time. For inspiration, Steve Jobs often looked to his role model Bob Dylan who refused to stand still and settle even when he was at the top of his fame (Schlender and Jobs, 1998). Many other successful artists keep doing mindlessly what made them successful in the first place. They are afraid to evolve or take new risks, and therefore they get stale. Jobs noted that if artists do not keep on risking failure, they are no more truly creative artists. Bob Dylan and Picasso were constantly risking failure.

\section{Kodak's Failure To Click}

A series of successive strategic leaders at Eastman Kodak have been not too willing to switch from their low-cost leadership strategy of photographic film to a more innovative digital imaging based product-differentiation strategy (Gamble and Gehani, 2013; Gehani, 1998). George Eastman, the founding-leader of Eastman Kodak, pioneered the portable photographic film and camera technologies in 1880s. These photographic film products were radical innovations at that time, because taking photographs conventionally took 6-8 hours sitting under blaring sunlight. Taking pictures required using bulky and messy freshly coated light-sensitive glass plates. With Eastman's radical innovations, Kodak dominated the photographic film market worldwide for many decades, and generated huge economies of scale and manufacturing speed until the 1970s.

Gradually, other competitors, such as Fuji-Photo in Japan and Agfa in Germany, entered and carved out big slices of the global photographic film and camera markets for themselves. The scientists and engineers in Kodak's research center in Rochester, New York invented and patented some key components of digital imaging technology. However, the strategic leaders at Eastman Kodak were not willing to cannibalize even the smallest slices of their dwindling market share of photographic film business which still returned high profit margins. 
In 198I, Sony entered the photo-imaging market by launching a disruptive radical innovation in the form of Mavica digital camera. Sony's early digital camera was expensive and with low image resolution. But the digital images captured by Mavica offered unique competitive advantages with their ability to be stored, manipulated, and transmitted easily over long distances. Gradually, the price of digital cameras came down significantly and the quality of digital images went up remarkably. Many successive strategic leaders at Kodak continued to deny the accelerating assault of innovative digital imaging products on photographic film markets (Gamble and Gehani, 2013). They refused to switch from pursuing low-cost mass-market leadership, and transforming to product-innovation driven differentiated strategy. This lack of willingness to change with the shifting market competition led Kodak towards declaration of chapter - II bankruptcy in 2012 (Gamble and Gehani, 20I3).

\section{Multi - Level Transformation}

Many strategic leaders prefer to make incremental transactional changes with low risk levels. They rely heavily on doing business-as-usual by becoming lean, reducing waste, or by outsourcing offshore, to reduce their costs and improve their profits incrementally. These cost-cutting efforts, as in the case of Eastman Kodak, are accompanied by periodic layoffs of large number of employees - with or without significant improvements in productivity (Gehani, 2008). Pursuit of radical transformation and disruptive organizational change from low-cost leadership strategy to product-differentiation strategy, on the other hand, requires not only an innovative strategic leader but also a genuine buy-in from agile teamleaders, operational followers, and responsive stakeholders.

\section{Evolving Leader-Member-Exchange}

More than ten years earlier, Gehani (2002) noted that the turbulent global markets in the 1990s, after the fall of many state-owned communist economies in 1989, demanded an evolution of leader-member exchange (LMX) relationship between innovative strategic leaders and their multiple levels of followers. Such mega shifts in global market environments demanded new strategic leadership approaches (Fukuyama, 1999). Traditionally, many high performing enterprises have relied on either charismatic or transactional leaders (Bass and Avalio, 1994; Nadler and Tushman, 1990). As the market environments become more turbulent with disequilibrium (D'Aveni, 1994; 1999), the transactional or charismatic leaders do not have the required dynamic capabilities to sustain their competitive advantages. These strategic leaders have to increasingly rely on their boundary-spanning team leaders and operational-level followers.
These diverse levels of followers are closer to the customers and markets where many turbulent shifts start. The strategic leaders in most enterprises must, therefore, rely more heavily on the team-level leaders and operational-level followers to bring about any transformational changes. Gehani (2002) proposed that market-oriented lateral strategic level leaders are more willing to interact and exchange with their team leaders and operational-level followers as more equal leaders on critical innovative projects.

Due to the paucity or generalizeability of many innovative strategic leaders transforming their enterprises pursuing low-cost leadership strategy into innovative product differentiation strategy, it is impractical to use a cross-sectional quantitative analysis. Therefore, we will illustrate the key concepts by using an empirical qualitative longitudinal study of the process of strategic transformation process at a composite of a large family-owned privately held U.S. enterprise.

\section{In This Research Study}

To explore how innovative strategic leaders can effectively and efficiently transform their enterprises pursuing low-cost leadership strategy to switch to relying on product innovation driven strategy, we illustrate by examining and analyzing the practices and experiences of a composite privately held large textile company Fabrick Co. (the actual name of the companies in the composite enterprise are withheld for confidentiality reasons). Fabrick Co. is based in the MidWestern region of the United States, with annual revenues of more than $\$ 3$ billion in 2012. Over 9,600 employees working in three strategic business unit divisions and four functional departments of Fabrick Co supplied more than 120,000 different SKUs of fabrics and other accessories to a wide variety of large apparel retailers like Limited, Gap, Abrocombie \& Fitch, Chico, Anthropologie, and others.

In the past, the strategic leaders at Fabrick Co were traditionally quite successful in growing the company by pursuing low-cost leadership strategy. However, with the recent deregulation of international textile trade and elimination of national textile quotas, there has been a surge in low-cost imports to the U.S. and Western Europe from China, India, Thailand and other low-cost countries. As a result, the strategic governance and the board of directors of the Fabrick Co. have been forced to consider migrating the enterprise to innovation driven product differentiation strategy.

Over the past three decades, Fabrick Co. first grew organically from within, and then grew inorganically by acquisitions. The company was originally founded in the 1970s by a highly innovative leader who supplied specialty fabrics to exclusive clients. During the 1980s and 1990s, Fabrick Co. acquired and consolidated a number of struggling rival fabric suppli- 
ers who were unable to sustain their competitiveness in an increasingly intense competitive market. As a result of these acquisitions and consolidations, the company started growing in the early 2000 s by primarily pursuing low-cost leadership strategy.

The acquisitions were integrated and the company was restructured into three divisions: the whole-sale fabric division, the retail fabric division, and the accessories division. These divisions were supported by four departments: marketing and distribution department, information technology department, finance and accounting department, and human talent management department. A number of different consultants were retained to help implement lean production practices. Six-sigma projects for waste reduction were encouraged and incentivized across the three divisions and the four supportive departments of Fabrick Co. enterprise. A low-cost leadership culture was ingrained deeply and widely.

Since the 2008 financial recession, however, it became hard to sustain Fabrick's growth momentum with low-cost leadership strategy - which yielded diminishing returns. Many of Fabrick Co's major customers developed alternate global sources in China and India, and developed them as alternate suppliers of competing product lines. The Fabrick Co. board of directors and family owners decided that its low-cost leadership strategy was shrinking its earnings rapidly. This strategy had become counter-productive to its growth, and therefore it was no longer sustainable. The company's board asked the previous CEO to step-up as chairman in January 2009, and appointed a new CEO from outside.

CEO Angela Jones was hired from a highly innovative clothing retailer, a major potential customer of Fabrick Co. Her mandate was to transform Fabrick Co. into a product innovation driven enterprise. Her performance bonus was tied to top-line revenue growth, as well as the percent sales and profit margins from new radically innovative products she would launch. She was offered a significant stock option, which would be vested after a substantial increase in sales and earnings. Her 'skin was in the game.'

\section{Research Method Used}

The primary focus of this qualitative research study is to carefully examine and illustrate the processes involved in a strategic leader's conscious strategic transformation of a large established enterprise from pursuing low-cost leadership strategy to product-differentiation strategy.

This research study is based on Grounded Theory Methodology (GTM), which predicates a rigorous quantitative interpretation of empirical observations and data by organizing these into an exploratory theoretical framework (Glaser and
Strauss, 1967; Strauss and Corbin, 1998). Such generation, collection, and qualitative analysis of observations has more applicability (than more common quantitative research studies) for many management practitioners as well as business educators (Turner, 1983). In this context, it is generally accepted by many researchers that it is impossible to carry out any research study without some guidance from previous theoretical frameworks (Melnyk, Hanson, and Calantone. 2010). We, therefore, frame our empirical research study in the context of two basic theoretical frameworks described below. These two frameworks are in addition to the evolving LMX theory perspective mentioned before.

We use in this study a multi-level approach by examining the execution of product innovation strategy at not only a strategic leader level, but also at a follower team-leader level, at an operational operator level, and at stakeholder level. Multiple extended interviews are required at each level. Each interview must follow a prescribed case-study protocol. Multiple interviewers are often used for each interview for robustness and to avoid subjective biases. This is supplemented with information gathered from secondary sources. The stories people at different levels share may not always clearly provide their reasons, but these stories provide clear glimpses of what drives their behaviors.

Such multi-level approach has been found to be superior than a single-level approach often used that erroneously assumes that a radical product innovation can be appropriated primarily to the efforts of a visionary strategic leader (or an agile follower, or a responsive stakeholder such as an innovative supplier). Many observers in popular media, and some researchers, have erroneously attributed the series of Apple's radical product innovations such as iMac, iPod, iTunes, iPhone, and iPad primarily to the visionary leadership of Apple co-founder Steve Jobs (Kahney, 2008). Very little efforts were devoted to study the roles and contributions of teamleaders, operators, and stakeholders.

This research study also relies on agency theory (Eisenhardt, 1989), which postulates interactions between principals and agents. In this research study, a strategic leader as a principal sets a vision and the over-arching goals for the enterprise to be innovative, but the strategic leader alone cannot implement these transformational changes. The implementation and execution of the strategic leader's vision and goals become the primary responsibility of the agents or the followers, such as tactical team leaders and operational-level followers. The interactions, trust, and the contracts between the principal innovative strategic leader and the inspired follower agents play critical roles in the timely completion of the transformation and market launch of radical product innovations. 


\section{Critical Observations and Lessons Learned}

As mentioned before, the illustrative information and the observations were gathered at four different levels: (I) strategic leader-level, (2) tactical team-manager level, (3) operational follower level, and (4) a stakeholder customer/supplier level. Given below are the lessons drawn from such observations and gathered information.

\section{Lessons At Strategic Leader - Level:}

\section{Using Innovative Mindfulness}

In order for a low-cost strategy driven enterprise to transform into an innovative product-differentiation driven enterprise, it needs an innovative strategic leader who envisions and champions the strategic transformation of the enterprise from the highest level. The innovative strategic leader has to be a front-end creative artist, as well as a backend inspiring entrepreneur. The strategic innovative leaders must identify fleeting new opportunities and capture these effectively and efficiently. The innovative strategic leader must be not only a transformational leader with top-down envisioning, but also a servant leader facilitating bottom-up nurturing of the followers. Based on our direct observations and gathered information, transforming an enterprise from low-cost leadership strategy to a product innovation driven strategy requires the following key initiatives from the highest-level of the enterprise.

\section{Investing in New Technology To Innovate Traditional Products}

Soon after taking over, CEO Angela Jones took three months to visit all the divisions and carefully observe the practices in different divisions. She noted that Fabrick Co. was in a steep downward spiral. She carefully examined all the products Fabrick Co. sold. In the past three years, Fabrick Co. had slowly degenerated to become a me-too fabric and accessory supplier. As fewer and fewer customers were buying the commoditized product lines it offered, the company was rapidly bleeding cash and losing market share. The investors and family owners were unhappy, and the company's debt rating was slipping down into the basement. It was merely three months away from bankruptcy.

One day CEO Jones called a meeting of the tactical leaders of all the three divisions and the four supporting departments in her office. She wrote down on a white board in big letters: WHAT IS WRONG WITH FABRICK CO.? The division and department leaders shuffled their feet waiting for the axe to fall on their heads. Someone mentioned financial recession. Another divisional leader pointed out to the escalating global competition from low-cost coun- tries. Jones did not seem to be impressed. The leader from the Human Talent department offered a declining morale in employees as the cause of the company's fall. They were expecting Jones to blame the division and department teamleaders for the deteriorating financial condition. Instead, Jones blasted: OUR PRODUCTS DON'T SELL BECAUSE THEY TURNED INTO COMMODITIES.

Jones listed how as the chief buyer for a major retail chain she had noted, more than five years before the onset of the 2008 financial crisis, a steady decline in the quality of Fabrick Co. products and after-sales service. She felt that whereas Fabrick Co. offered more and more lines of products, very few of these products stood apart from the commodity goods coming out of China. Jones had frequently visited India, and saw some amazing fabrics and accessories based on the long-held historical traditions of India. Many of these products were made from natural fibers and renewable sources (rather than petroleum oil-based plastics and synthetic fibers used in the products produced in China). She felt that with the growing awareness for climate change and environmental protection among many of their high-end customers, the time had come to introduce to them some innovative natural fabrics modified with the latest developments in new emerging technologies.

These green product innovations would leverage the latest developments in the emerging environmental-friendly technologies such as nano technology and new thin-film surface-coating treatments. Nano technology allows use of significantly smaller quantities of natural dyes and additives to dramatically enhance the performance characteristics of many natural fibers, fabrics, and accessories. New advances in thin-film surface coating technologies can help treat the fabrics made from natural fibers to make them odor, mold, and stain resistant. The treated fabrics would have wicking properties to absorb sweat and leave behind a feeling of freshness with clean dry skin. Odorless clothing has a huge market potential in the hunter clothing market.

CEO Jones knew that launching a series of innovative green products, based on the latest developments in nano and thinfilm surface treatment technologies, would not be sufficient to quickly change the customers' perception about Fabrick Co. There was a deeply ingrained image of Fabrick Co. as a low-cost supplier of commodity goods. She, therefore, proposed a new $\$ 3$ million company-wide advertising campaign promoting environmental protection. This would start with multiple 30 second spots in the National Basketball March Madness broadcasts. She created the fifth department of Corporate Reputation, and entrusted it to a newly hired dynamic brand promoter who had worked with Angela Jones in her previous company. 


\section{Focus on the Select Few}

One of the first few things Jones wanted to do was to refocus Fabrick Co. She noted that over the past few years, Fabrick Co. had spread too widely into 120,000 different product lines of fabrics and accessories in a wide variety of price ranges. Servicing their major customers with all these multiple lines required heavy inventories, estimated at $\$ 360$ million a year. In the past, Fabrick Co. frequently wroteoff large amounts for unsold or obsolete inventories. CEO Jones decided to eliminate the low-end product lines, and retain only the high-end 75,000 specialty product lines and accessories. She solicited all the Frederick Co. employees to suggest the select few product lines that need to be retained. For any lines that a division wanted to keep, it had to make a business case why it must be retained based on its earnings contribution and profit margin. The division heads had to prove to Jones that a particular product line had a sustainable competitive advantage, based on either a unique technological edge or a close customer relationship.

This exercise for slashing-and-burning unneeded product lines lasted day after day for about six weeks. Jones listened calmly, and asked many questions:

A. How was the product produced?

B. How was it marketed?

C.What would they do if the budget was doubled or halved? D. How did the product line align and contribute to the innovation driven business strategy of the firm?

She was mindfully reflective. She urged everyone at Fabrick Co. to focus, and retain only what they were best at offering. Finally, when the dust settled, the reduction in product lines substantially decreased the need to maintain heavy inventories. The inventory levels came down from $\$ 360$ million to $\$ 150$ million within a year. This boosted the earnings significantly by $\$ 63$ million at the end of the year. This was a great immediate reward. But what would sustain such success next?

\section{Balancing the Role of Performance Outcome Goals}

There is a paradoxical challenge for innovative strategic leaders in balancing the relationship between inspiring product innovation, and setting clear performance outcome goals. On one hand, the Goal-setting Theory proposes that performance of an enterprise is positively correlated with the articulation of precise goals (Locke and Latham, 1990). Setting performance standards clearly communicates across the enterprise what is needed, and how incentives are appropriated in alignment with the specified performance goals (Melnyk and Stewart, 2004). On the other hand, it has been often found empirically that an over-emphasis of goals hampers encouragement of innovation.
To avoid such distraction, often radical innovation projects are isolated and located away from the rest of a well-established enterprise (Markides, 2006). For example, in 1980, when the strategic leaders at IBM decided to compete with Apple by entering the personal computer (PC) market, they located their PC skunk-works to Florida, far away from IBM's headquarters in upstate New York (Gehani, 1998).

During the past 10 years, the Emerging Business Opportunities (EBO) program has helped IBM gain significant growth and innovative success with networked data storage and blade servers (Anthony and Christensen, 20I2). One key driver of this innovative success was that the EBO team leaders were evaluated by not just their financial returns, but primarily by whether these team managers learned from early failures and responded adaptively in a timely manner.

For many well-established enterprises and strategic leaders, it is often hard to walk away from relying on their conventional cost-cutting strategies and performance metrics. Even the most innovative strategic leaders and enterprises cannot ignore reducing the cost of their innovative products in order to stay competitive with their cost - leadership rivals. Short-term cost cutting often must run side by side with long-term radical innovation. However, prior reliance and success with incremental improvements has been observed to be negatively correlated with a successful pursuit of radical innovation (Benner and Tushman, 2003).

\section{Leveraging Crisis to Speed-up Change and Buy-in}

In this context of facilitating change, a crisis (either real or fabricated by a strategic leader) can help an innovative leader transform an enterprise from pursuing cost-cutting goals to radical product innovation goals. (Carmeli and Schauboeck, 2008; Kim, 1998).

Considering the dire financial circumstances under which CEO Jones was hired from outside, the strategic leader used the financial crisis to gain a buy-in and a speedier change from her lowerlevel followers and external stake-holders. Jones felt that the crisis situation helped her layoff almost 3,300 out of 9,600 employees. Another 450 employees were furloughed for temporary periods. She also hand-picked 30 highly creative employees and moved them into the fourth new Green Innovation Fabrics and Accessories Division she started. A number of other cost-saving methods related to travel, vacations, and pensions were instituted without much resistance because of the impending crisis situation. 


\section{Lessons From Tactical-Level}

\section{Divisional Managers}

Typically, at the senior manager level in an enterprise one observes a resistance to change often involved with a radical innovation. This resistance to change may result in either obstruction or overt unwillingness to implement the strategic leader's new vision. There are a number of key lessons to mitigate such lack of support for the strategic innovative change mandated from above.

\section{Mindless Rut and Status Quo}

Some divisional-level team leaders are too complacent to change because they are stuck in a mindless rut. They are comfortable doing the same familiar thing over and over again that they have been doing over the past many years. They may not be awake to their likes and dislikes, and they are not aware of the shifting opportunities in the marketplace. They know how to cut costs, but they are afraid of taking risks to pursue radical new innovations. They know that the old way of low-cost leadership was not working any more. But they also may not know how the proposed new way of pursuing product innovations would pay off rich dividends to the company, and to themselves personally.

Many of these older managers are also somewhat scared that the new innovative ways would put them at a competitive disadvantage relative to the new younger employees who are less hardened, and more open to creative new ideas. The older managers tend not to have the Internet and digital multi-media savvy of the younger generation employees. The younger employees are often much better at finding answers to any new questions that arise related to the new product innovations. At times the older division-heads wonder if the younger seemingly clueless generation even knows what they do not know.

\section{Limited Comprehension}

Limited comprehension is another common source of resistance to change and organizational transformation. Whereas the leader at the highest strategic level may have a clear view of the innovative disruptive new vision, this innovative vision may not be fully or clearly communicated to the middlelevel managers who are expected to execute the strategic leader's innovative vision. Whereas the strategic leader at the top is clearly aware of the need to develop and market radical product innovations that are new to the textiles industry, the divisional-level managers may not be tacitly aware of these implicit requirements new to the industry and new to the company.
The limited comprehension may also apply to the shifting performance metrics. Whereas the cost-leadership strategy measures performance by the unit cost and profit margin metrics, the 'newness' in product innovation is hard to assess. Many hard to answer questions arise:

A. Is a product just incrementally improved, or is it a radical new product?

B.Who determines that difference?

C. Will the customers fully comprehend the innovative products that they have not seen yet?

D. Will the targeted customers be willing to pay premium prices for the differentiated 'newness'?

Whereas the tactical team managers knew the conventional fabric treatments that improve the performance and utility of a textile fabric, these managers required much deeper comprehension of nano technology and how this would radically innovate the performance of natural textile fabrics. Some of the newly invented thin-film surface treatments are far more sophisticated and complex than the conventional treatments used for synthetic textiles.

\section{Limited Trust and Buy-In}

The mindless rut and a limited comprehension mentioned above can often lead to a limited buy-in by the senior managers and tactical team leaders. Some tactical team-leaders may want to seriously question if the innovation-driven product differentiated strategy is relevant or even financially viable for the traditional and mature goods such as textile fabrics for apparel. This resistance is likely to be more intense from the product divisions which still have substantial market shares and profit margins. A similar resistance and limited buy-in of team leaders was observed at Eastman Kodak as many of the senior managers in the photographic film division with high market shares and profit margin remained skeptic for too long about the need to switch more aggressively to more innovative digital imaging (Gamble and Gehani, 20I3). The leaders of market segments often fail to see the need to change, or to 'fix' what does not seem to be broken.

Some resistors to change or innovate radically deny that there can be any radical innovations in traditional industries such as clothing. These managers assert that people have been using clothing for centuries, and therefore it is hard to introduce anything radically different. Others feel that costcutting and incremental improvements still have long way to produce good financial results, and that radical innovations may be too risky or unpredictable for a firm with serious financial constraints. They view the risk-to-reward relationships in radical product innovations very differently from the way their strategic leader sees these. 


\section{Time Lags}

Radical product innovations also involve unpredictable large time lags between deployment of financial and temporal resources (as in design, feasibility studies, or prototype making), and the accrual of benefits (as in gaining market share, or higher profit margin). Many conventional managers prefer their age-old reliance on process-based productivity improvements over making radical new bets in new untested market segments. They also fear that initially their own performance, and performance-based incentives, may suffer because of the initial investments required in frontend exploration, trials, and market tests needed to develop and launch radical product innovations.

Radical innovations also require patience and persistence. Market success is not likely to happen with innovations overnight. Gaining market penetration and customer acceptance takes significantly large amounts of time. Instant block-buster successes are rare. Senior-level managers may need to re-learn and be willing to postpone their satisfaction and gratification from their short-term efforts and investments - especially when they can least afford to do so because of their financial and time constraints.

\section{Unwillingness to Risk and Fail}

As we noted before in the introduction section, innovative strategic leaders and tactical team-level managers must be willing to fail, learn from their failures, and resiliently move on. Steve Jobs looked up to Bob Dylan and Picasso as the innovative artists who were willing to fail again and again while attempting to innovate. Unfortunately, after the 2008 recession, very few firms had the financial slack or the will to accept failure. Sometimes, they did not have the process flexibility needed to produce radical product innovations. Or they may not have the financial resources needed to purchase, install, and commission more flexible production facilities to produce the proposed product innovations.

Some firms are also not ready to succeed from their radical innovations. If their innovations become successful, they require substantially additional resources to capitalize from their breakthrough success. They may not have such resources to invest in capacity building. With lack of slack resources, some managers may be afraid to get trapped in the 'valley of death.' This realization of euphoria of success mixed with anxiety to scale up can easily cause strategic dissonance (Burgelman and Grove, 1996).

\section{Lessons From Operations - Level Followers}

The operational-level followers are far more specialized in their functions than their upper level leaders. They see their company's strategic transformation from low-cost strategy to product-innovation driven differentiated strategy as inconvenience and irksome. They may suffer from some of the same challenges as noted earlier for the tactical-level team-leaders and divisional managers.

\section{Mindless Rut and Resistance to Change}

Like the tactical-level team leaders and divisional managers, operational level followers may also feel more comfortable in doing what has been specified and negotiated from one collective bargaining contract to the next by their guilds or unions (in union shop enterprises). The operational level workers, who are members of unions, may be even more rigid in switching to any new innovative tasks, or trying some innovative new ways. We have heard older staff members used to filling paper forms resist using computers for filling forms online.

\section{Limited Comprehension}

Reducing cost or eliminating waste, to improve efficiency or be more lean, are fairly straight-forward guidelines for most operational-level employees to follow. 'Be innovative' or 'be more customer-responsive' are much more abstract ideas to comprehend for many operational - level employees. The operations - level followers need more precise distinction between incremental improvements and radical innovations. Their strategic leaders or tactical-level division managers set over-arching goals to be radically innovative. This may not help the operations-level followers to figure out how to go about accomplishing such over-arching goals. Many of these followers may continue to use currently used procedures, with very limited innovative outcomes.

\section{Limited Buy-In}

Most operational-level followers are often paid by piecerates. They rarely receive any incentives to try out fuzzy new innovative ways. Such innovative new ways often reduce their outputs and productivity, and thereby their take-home pay. Many operators are willing to try out new innovative ways while they are paid to work, as long as their take-home pay is either not reduced, or it is somewhat increased. The innovative new products produced as per customers' orders, often have shorter production runs and larger inventory levels than the more commoditized older mature products and accessories. Switching from low-cost commodity products (like photographic film in Eastman Kodak) to radically innovative products (such as digital imaging for Eastman Kodak) also represents a shift in the power and influence of the different operational-level followers with different training backgrounds. At Fabrick Co. the operation - level followers were expected to build their competencies in environmentally sustainable green products and processes. 


\section{Skill Lags}

More than the time-lags, the operational-level followers are more likely to be concerned with a lag in their skills and education that they must have to produce radically innovative products. For example, at Kodak, the value of chemists and chemical engineers producing photographic film declined at the expense of a growing influence of employees with computer science and electronics background producing digital imaging products. At Fabrick Co., there was a growing need for the employees with expertise in nano technology and thin-film surface coating technology. This shifted the influence and performance from textile engineers and buyers to chemists and chemical engineers familiar with nano technology and thin-film surface technology.

\section{Unwillingness to Risk and Fail}

Finally, there is a bigger resistance to try out new ways and new means among operators in order to produce innovative new environment-friendly green products. The operationslevel followers must touch and use the new materials, and deliver a consistently high productivity as well as a high quality. This requires a lot of trial and error at the operations level. Fabrick Co. required a new culture where risk taking was encouraged, and failures were tolerated. In the past, there was a mature rigid culture where costly failures were looked down upon and often punished. CEO Jones must work hard to define and clearly communicate a new culture and a new compensation system promoting innovation.

In addition to building a new culture, the compensation and incentives for operators must be realigned to the overall strategic mission to be innovative and environment - friendly. Most operators tend to behave to maximize their economic and psychic utility. Therefore, their compensations and incentives must be carefully realigned to the overall corporate strategy. In addition to such rewards, new programs are needed for recognition of the operators who suggest and adopt innovative ideas. Some of the best practices can be adopted from Japanese enterprises such as Honda and Toyota, where each employee suggests more than 200 suggestions per year (Gehani, 1998).

\section{Lessons From Stake-Holder Level:}

\section{Courting Customers And Engaging Suppliers}

A strategic transformation involves balancing the multiple demands of an organization's different stakeholders as related to the strategic leader's new innovation driven strategic goals. According to Ackerman and Eden (20I I), whereas there is extensive literature that discusses management of stakeholders, the key concepts are not well developed to make these useful in practice. Stakeholders not only include those entities that support the enterprise (Freeman and Reed, 1983), but also those entities that are affected by the organization (Cross and Prusak, 2002).

Strategic leaders and tactical-team managers need to manage the dynamic influences of their external stakeholders effectively in order to realize their intended strategic transformation from relying on low-cost strategy to innovation driven strategy (Cummings and Doh, 2000). According to Porter (1980), two key groups of stakeholders whose bargaining powers significantly impact the potential profits of an enterprise are buyers and suppliers. The dynamic influences of these stakeholders are discussed below.

\section{Courting the Customers}

CEO Jones's innovation-differentiated strategy demanded a close courting of key customers and buyers. Jones started a detailed sales-driven planning process, whereby the key customers' changing preferences and requirements drove the capacity monitoring and capacity building initiatives within Fabrick Co. Using an A - B - C analysis, a new sales protocol had to be developed. The major $\mathrm{A}$ - level customers generating the highest sales revenue were to be contacted almost every day. The medium B - level customers, with somewhat lesser but still significant sales volumes, were to be contacted once a week. And, the C - level customers, ordering primarily commodity - like products were to be contacted once in two weeks. The salesmen at Fabrick Co. were screened and ranked based on their empathy and persistence, rather than on their aggressive persuasiveness in selling. The most empathetic and persistent salesmen were assigned the $\mathrm{A}$ - level clients and major accounts.

All the salesmen at Fabrick Co. needed to be retrained to switch from relying on traditional transactional selling, to relying more on relational selling. In transactional selling, the Fabrick salesmen focused on 'asking for the order' and 'closing the deal'. In relational selling, the retrained salesmen focused on the customers' 'pain' in sustaining their profits and competitive advantages, and tried to offer sales solutions to mitigate such pain.

This change took substantial time for the Fabrick Co. salesmen to earn and build trust of the key customers. First, some past learning had to be unlearned. In the past, some Fabrick Co. salesmen had been often times inconsistent in making their promised deliveries. They had monitored shipments at their end, and often did not follow when these shipments arrived at the customers' warehouses. This had upset many customers and caused a lot of lost sales. Only a consistent track record of delivering as promised, time after time, would help improve the trust level of the customers. 


\section{Supplier Engagement}

The new innovation-differentiated products relied heavily on an intimate engagement of key suppliers. Specialized and exclusive suppliers were identified, carefully screened, and sourced in India. Instead of the hands-off relationships that Fabrick Co. had with many suppliers in the past, a more partnership like relationship was cultivated with the selected fewer strategic suppliers. In the past, Fabrick Co. used 900 suppliers to service their 120,000 product lines. This was carefully whittled down to I50 key suppliers servicing 60,000 product lines.

The craftsmen and owners of the cottage industry of India making the differentiated natural fabrics and accessories for Fabrick Co., had to be retrained in quality assurance. They needed to be significantly scaled up for economies of scale. None of these exotic natural goods were currently being offered by Fabrick Co. or its key rivals. CEO Jones shared with the tactical team-leaders that she saw a huge market potential in launching such green product innovations. She, therefore, proposed to start the new Green Fabrics and Accessories division, primarily developing radical new products based on renewable natural and bio-degradable resources. This fourth division was charged to account for about $30 \%$ of the total sales revenue of Fabrick Co. in five years.

\section{Implications For Practitioners And Research}

This research study has empirically illustrated what takes place when an innovative strategic leader attempts to transform an enterprise relying on low-cost leadership strategy into an enterprise driven by innovative product differentiated strategy. To do so effectively, how must strategic leaders change their relationship with their multi-level followers?

\section{Patterns of a Leader's Influence}

Gehani (20II) has noted that innovative strategic leaders follow a pattern of five different orientations to influence their followers' creativity and innovation. This study elaborated on the characteristics of an innovative strategic leader's (I) position orientation, (2) partnership orientation, (3) production task orientation, (4) people's development orientation, and (5) personhood mindful orientation. With dynamic hyper-intensive markets, and increasingly innovation-driven global competition, strategic leaders may need to evolve from the fourth-level servant leaders facilitating team-leaders and operations-level followers in a relatively predictable market environment (Greenleaf, 1977), to the fifth-level mindful lateral leaders.

The mindful innovative leaders influence their followers by respecting the authenticity of their followers' personhood.
Many employees, at tactical team manager level or at operational follower level, wear masks (or an artificial persona) most of the time that they are at work. During crises situations, these masks come off, and the frustrated angry employees, either team-leaders or operational followers, peek from underneath their masks. Mindful innovative leaders seek their followers' authentic core capabilities and persona to craft their innovative visions (Klein and Izzo, 1998). They balance their top-down envisioning with a nurturing of bottom-up entrepreneuring by their followers.

\section{From Product Differentiated Innovation To Value Driven Innovation}

Furthermore, is this strategic transformation always needed? Must all innovative strategic leaders make highly disruptive transformational changes from low-cost leadership to innovative product-differentiated strategy? Must these enterprises shed their long-held cost-cutting cultures to create and adopt an altogether new innovation-driven culture based on premium-priced differentiated products? Would all of these enterprises make such drastic transformation successfully?

Value-based innovation may be a more practical and less disruptive alternative for strategic leaders seeking to gain sustainable competitive advantage. The recently retired chairman Ratan Tata of India's large conglomerate Tata Group, proposed a value-based innovative Nano mini-car for estimated 900 hundred million potential new customers at the 'bottom of the economic pyramid' in India and in other parts of the world (Gehani, 20I3). The Tata Nano mini-car costs only Indian rupees 100,000 or US\$2,200 (in 2008 currency exchange rate), and provides a safe water-proof mode of transportation for the families of bottom-of-the-pyramid customers. The innovative strategic leader Ratan Tata resisted the attempt for Tata Motors to rely exclusively on the premium-priced product innovations (such as Jaguar and Land Rover brands he acquired from Ford in 2008).

Many other value-based product innovations, such as Jaipur prosthetic foot, Southwest Airlines, and computer-based animation film Toy Story are other examples of successful transformation of innovative enterprises (Thompson et al., 20I3). These enterprises retained their core DNA of costcutting cultures, and blended these with the state-of-the art innovation. Strategic leaders may, therefore, consider pursuing value-based innovation strategy instead of rushing to pursue a more disruptive product-differentiated innovation strategy. 


\section{References}

ACKERMAN, Fran and Eden, Colin. 20I I. Strategic management of stakeholders:Theory and practice. Long Range Planning, 44: I79- 196.

ANTHONY, Scott, and Christensen, Clayton M. 20I2. The Empire strikes back. Technology Review, Jan./Feb.: 66-68.

BASS, B.M. and Avolio, B. J. 1994. Transformational leadership and organizational culture. International Journal of Public Administration, I7(3): 54I - 554 .

BENNER, M. J. and Tushman, M. L. 2003. Exploitation, exploration and process management: The Productivity Dilemma revisited. Academy of Management Review, 28(2): 238 - 256.

BURGELMAN, R. A. and Grove, A.S. 1996. Strategic dissonance. California Management Review, 38(2): 8 - 18.

CARNELI, A. and Schaubroeck, J. 2008. Organizational crisis - preparedness: importance of learning from failures. Long Range Planning, 4I(2): I77 - 196.

CHATTERJEE, S. 2009. The keys to successful acquisition programs. Long Range Planning, 42: 137 - 163.

CROSS, R. and Prusak, L. 2002.The people who make organizations go - or stop. Harvard Business Review, 80(6, Jun.): I04-III.

CUMMINGS, J. L. and Doh, J. P., 2000. Identifying who matters: Mapping key players in multiple environments, California Management Review, 42: 83-104.

D’AVENI, R. A. 1994. Hypercompetition: Managing the Dynamics of Strategic Maneuvering. New York: Free Press.

D'AVENI, R.A. 1999. Strategic supremacy through disruption and dominance, Sloan Management Review, 40(3, Spring): $127-135$.

EISENHARDT, K. M. 1989. Agency theory: An assessment and review. Academy of Management Review, I4(I): 57 - 74.

FREEMAN, R. E. and Reed, D. L., 1983. Stakeholders and shareholders: A new perspective in corporate governance. California Management Review, 25(3): 88-106.

FUKUYAMA, F. 1999. The Great Disruption. New York: Free Press.
GAMBLE, J. E. and Gehani, R. Ray. 2013. Eastman Kodak. Eastman Kodak. In Thompson, Arthur A., Peteraf, Margaret A., Gamble, John E., and Strickland III, A. J. Crafting and Executing Strategy. New York: McGraw-Hill. Case study\#16: C212-219.

GEHANI, R. Ray. 1992. Concurrent product development for fast track corporations. Long Range Planning, 25(6): 40-47.

GEHANI, R. Ray. 1993. Vision management. Interfaces, 23(3, May/June): $127-128$.

GEHANI, R. Ray. 1998. Management of Technology and Operations. New York: John Wiley \& Sons.

GEHANI, R. Ray. 2002. Evolving Leader - Member Exchange (LMX) Theory and market oriented lateral leaders in turbulent global markets. Marketing Management Journal, I2(2, Fall): $53-66$.

GEHANI, R. Ray. 20 I0. Eastman Kodak: Strategy for innovating business models. Innovation and Enterprise. Rochester, New York: Globalhood Corp.

GEHANI, R. Ray. 20I I. Individual creativity and the influence of mindful leaders on enterprise innovation. Journal of Technology Management and Innovation. 6(3): 82 - 91.

GEHANI, R. Ray. 2013. Innovative Mindful Leader and Valuebased Product Innovation. Ratan Tata and Nano Mini-car. Work in progress forthcoming.

GLASER, B. and Strauss, A. 1967. The Discovery of Grounded Theory: Strategies of Qualitative Research. London:Widenfeld and Nicholson.

GREENLEAF, Robert. 1977. Servant Leadership: A Journey into the Nature of Legitimate Power and Greatness. New York: Paulist Press.

KAHNEY, Leander. 2008. Inside Steve's Brain. New York: Portfolio/Penguin.

KIM, L. 1998. Crisis construction and organizational learning: Capability building in catching up at Hyundai Motor. Organization Science, 9(4): 506 - 521.

LOCK, E.A. and Latham, G. P. 1990. A Theory of Goal Setting and Task Performance. Englewood: Prentice-Hall.

MARKIDES, C. 2006. Disruptive innovation: Needfor better theory? Journal of Product Innovation Management, 23: 1925. 
MELNYK, Steven A., Hanson, John D., and Calantone, Roger J. 2010. Hitting the Target ... but Missing the Point: Resolving the Paradox of Strategic Transition. Long Range Planning, 43: 555-574.

MELNYK, S. A. and Stewart, D. M. 2004. Metrics and performance measurement in operation management: Dealing with the metrics maze. Journal of Operations Management, 22(3): 209.

NADLER, D.A. and Tushman, M. L. 1990. Beyond the charismatic leader: Leadership and organizational change. California Management Review, 32(2, winter): 77 - 97.

PORTER, M. E. 1980. Competitive Strategy:Techniques for Analyzing Industries and Competitors. New York: Free Press.

ROTHERMEL, F.T. and Hess, A. M. 2007. Building dynamic capabilities: Innovation driven by individual, firm, and networklevel effects. Organization Science, I8(6): 898 - 92 I.

SCHLENDER, Brent and Jobs, Steve. 1998. The Three Faces of Steve. Fortune, Nov. 9.Accessed online on March I5, 2013.

STRAUSS, A. and Corbin, J. 1998. Basics of Qualitative Research Grounded Theory: Procedures and Techniques. Thousand Oaks, CA: Sage Publications.

THOMPSON, Arthur A., Peteraf, Margaret A., Gamble, John E., and Strickland III, A. J. Crafting and Executing Strategy. New York: McGraw-Hill.

TURNER, B. A. 1983. The use of grounded theory for the qualitative analysis of organizational behavior. Journal of Management Studies, 20(3): 333-348. 